\title{
Synthesis of silver nanoparticles by using tea leaf extract from Camellia Sinensis
}

\author{
This article was published in the following Dove Press journal: \\ International Journal of Nanomedicine \\ I August 2012 \\ Number of times this article has been viewed
}

\section{Yuet Ying Loo' \\ Buong Woei Chieng² \\ Mitsuaki Nishibuchi ${ }^{3}$ \\ Son Radu'}

'Centre of Excellent for Food Safety Research, Faculty of Food Science and Technology, Universiti Putra Malaysia, Selangor, Malaysia; ${ }^{2}$ Department of Chemistry, Faculty of Science, Universiti Putra Malaysia, Selangor, Malaysia; ${ }^{3}$ Center for South East Asian Studies, Kyoto University, Kyoto, Japan

Correspondence: Son Radu Centre of Excellent for Food Safety Research, Faculty of Food Science and Technology, Universiti Putra Malaysia, 43400 UPM Serdang, Selangor, Malaysia Tel +6038946836 I

Fax+60389423552

Email son@putra.upm.edu.my
Abstract: The development of the biological synthesis of nanoparticles using microorganisms or plant extracts plays an important role in the field of nanotechnology as it is environmentally friendly and does not involve any harmful chemicals. In this study, the synthesis of silver nanoparticles using the leaves extract of Chinese tea from Camellia sinensis is reported. The synthesized nanoparticles were characterized using UV-vis spectroscopy, X-ray diffraction (XRD), transmission electron microscopy (TEM), and Fourier transform infrared (FTIR) spectroscopy. The XRD analysis shows that the synthesized silver nanoparticles are of facecentered cubic structure. Well-dispersed silver nanoparticles with an approximate size of $4 \mathrm{~nm}$ were observed in the TEM image. The application of the green synthesized nanoparticles can be used in many fields such as cosmetics, foods, and medicine.

Keywords: silver, nanoparticles, green synthesis, leaf extract, transmission electron microscopy, nanotechnology

\section{Introduction}

The development of toxicity free metal nanoparticles has become a great challenge in recent times. The primary challenge in this focal area is the maximization of the usage of environmental friendly materials in the generation of metal nanoparticles. Various chemical and physical methods have been employed to prepare silver nanoparticles with different sizes and shapes, such as UV irradiation, ${ }^{1,2}$ microware irradiation, ${ }^{3,4}$ chemical reduction, ${ }^{5-7}$ photochemical method, ${ }^{8,9}$ electron irradiation, ${ }^{10,11}$ and sonoelectrochemical method. ${ }^{12}$ However, most of the reported methods involve more than one step, high energy requirement, low material conversions, difficulty in purification, and hazardous chemicals. The chemical synthesis of nanoparticles may lead to the presence of some toxic chemical species adsorbed on the surface that may have adverse effects in its application. The synthesis of nanoparticles by green method can potentially eliminate this problem. Therefore, there is an urgent need to develop a green process of nanoparticle synthesis.

Green synthesis methods employing either biological microorganisms or plant extracts have emerged as a simple and alternative to chemical synthesis. Green synthesis provides advancements over chemical methods as it is environment friendly, cost effective, and easily scaled up for large scale synthesis. Generally, the green synthesis method involves three main steps, (1) solvent medium selection, (2) environmental benign reducing agent selection, and (3) non-toxic substances for nanoparticles stability selection. ${ }^{13}$ The synthesis of nanoparticles by using plant extracts can be advantageous 
over other biological processes because it eliminates the elaborate process of maintaining cell cultures and can be suitably scaled up for large scale production under nonaseptic environments.

Silver nanoparticles are well known as one of the most universal antimicrobial substances in the field of biology and medicine due to their strong biocidal effect against microbial species, which has been used for centuries to prevent and treat various diseases, most notably infections. ${ }^{14}$ Silver nanoparticles also reported to possess anti-fungal, ${ }^{15}$ anti-inflammatory, ${ }^{16}$ anti-viral, ${ }^{17}$ anti-angiogenesis ${ }^{18}$ and anti-platelet activity. ${ }^{19}$ Recently, the development of silver nanoparticles is expanding. They are now used as part of clothing, food containers, wound dressings, ointments, and implant coatings. Some silver nanoparticles' applications have received approval from the US Food and Drug Administration. ${ }^{20}$

$\mathrm{Pu}$-erh teas are known as medicinal tea in China. Pu-erh teas are reported to have high antioxidant properties and the ability to decrease the cholesterol, lower blood pressure, prevent cardiovascular diseases and enhance the normal flora in our gastrointestinal tract. ${ }^{21}$ In the present work, we have proposed a green chemical method for synthesizing Ag nanoparticles using pu-erh tea leaves extract from Camellia sinensis as reducing and capping agents. To the best of our knowledge, this study is new and presents a simple methodology to synthesize Ag nanoparticles efficiently at room temperature.

\section{Materials and methods Materials}

Pu-erh tea is traditionally made by the leaves of old wild tea trees of Camellia sinensis var. assamica, which are found in south-western China as well as the bordering tropical regions in Burma, Vietnam, Laos and eastern parts of India. The leaves are artificially fermented for 6 months to a year with microorganisms to produce pu-erh tea. Commercial pu-erh tea was purchased from local tea shop in Malaysia. Silver nitrate $\left(\mathrm{AgNO}_{3}\right)$ was purchased from Merck, Germany.

\section{Synthesis of silver nanoparticles}

The pu-erh tea leaves extract was prepared by weighing $10 \mathrm{~g}$ of pu-erh tea leaves in $500 \mathrm{~mL}$ beaker along with $100 \mathrm{~mL}$ of distilled water and maintained at $60^{\circ} \mathrm{C}$ for $10 \mathrm{~min}$ before decanting it. The solution was filtered by $0.45 \mu \mathrm{m}$ Milipore membrane filter and followed by $0.2 \mu \mathrm{m}$ Millipore membrane filter. For synthesis of silver nanoparticles, $100 \mathrm{~mL}$ of $\mathrm{AgNO}_{3}(1 \mathrm{mM})$ was reacted with $12 \mathrm{~mL}$ of the tea extract in
Erlenmeyer flask at room temperature. Any color changes of the solution were observed.

\section{Characterization}

The crystallinity and phases of the Ag nanoparticles were characterized by X-ray diffractometer (XRD-6000, Shimadzu, Japan) with $\mathrm{Cu}_{\mathrm{k} \alpha}$ radiation $(\lambda=1.5412 \AA)$ in the range of $10^{\circ}-80^{\circ}$ with $2 \%$ min scanning rate. The functional and composition of $\mathrm{Ag}$ nanoparticles were characterized by Fourier-Transform Infrared (FTIR, Perkin Elmer, Spectrum $\mathrm{BX}$ ) spectroscopy in the range $4000-280 \mathrm{~cm}^{-1}$. In addition, the optical property of prepared Ag nanoparticles was analyzed via UV-visible (UV-Vis, Perkin Elmer, Lambda 35) absorption double beam spectrophotometer with a deuterium and tungsten iodine lamp in the range from 300-600 nm at room temperature.

The morphology of the prepared Ag nanoparticles was observed by Transmission Electron Microscopy (TEM, Hitachi, H7100). Ag nanoparticles were sonicated for $15 \mathrm{~min}$ by a sonicator $(50 \mathrm{~Hz}$, Soniclean). Then, the dispersed solution was dipped to a copper grid at room temperature. After drying, sample was analyzed at $80 \mathrm{kV}$. The particle size distributions were determined using UTHSCSA Image Tool Program (version 3.00; Dental Diagnostic Science, UTHSCSA, San Antonio, TX).

\section{Results and discussion}

The color change was noted by visual observation in the Erlenmeyer flask which contains $\mathrm{AgNO}_{3}$ solution with pu-erh tea extract. The color of the $\mathrm{AgNO}_{3} /$ tea extract solution changed from colorless to light brown after 5 min and eventually to dark brown (Figure 1). This color change indicates the formation of Ag nanoparticles in the solution. Tea extract without $\mathrm{AgNO}_{3}$ did not show any color changes. The formation of Ag nanoparticles was further confirmed by

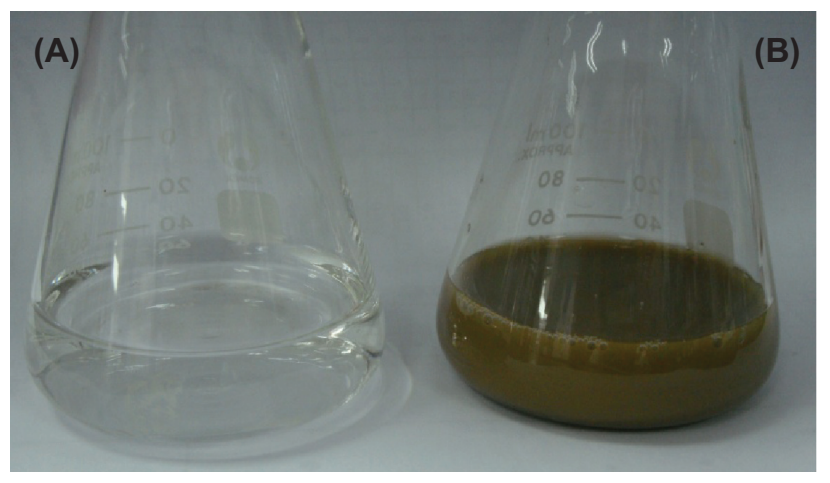

Figure I Aqueous solution of $10^{-3} \mathrm{MAgNO}_{3}$ with pu-erh tea leaves extract (A) before adding the tea extract and $(\mathbf{B})$ after addition of tea extract at 5 minutes. 
using UV-visible spectroscopy (UV-vis), X-ray diffraction (XRD), Fourier-Transform infrared spectroscopy (FTIR) and transmission electron microscopy (TEM).

Figure 2 shows XRD patterns for Ag nanoparticles synthesized by pu-erh tea leaves extract. Five main characteristic diffraction peaks for $\mathrm{Ag}$ were observed at $2 \theta=38.4,44.5,64.8,77.7$ and 81.7 , which correspond to the (111), (200), (220), (311), and (222) crystallographic planes of face-centered cubic (fcc) Ag crystals, respectively (JCPDS 00-004-0783). No peaks from any other phase were observed showing that single phase Ag with cubic structure nanoparticles have been obtained directly.

In general, the width of XRD peaks is related to crystallite size. Debye-Scherrer equation was used to determine average crystallite diameter from half width of the diffraction peaks: $\mathrm{D}=(\mathrm{k} \lambda) /(\beta \cos \theta)$, where $\mathrm{D}$ is mean crystallite size of the powder, $\lambda$ is the wavelength of $\mathrm{Cu}_{\mathrm{k \alpha}}, \beta$ is the full width at halfmaximum, $\theta$ is the Bragg diffraction angle and $\mathrm{k}$ is a constant. The (111) plane was chosen to calculate crystalline size. From Debye-Scherrer equation, the average crystallite size of silver nanoparticles synthesized is found to be $3.42 \mathrm{~nm}$.

Figure 3 shows the UV-vis absorption spectrum of the synthesized Ag nanoparticles. Silver nanoparticles have free electrons, which give surface Plasmon resonance (SPR) absorption band, due to the combined vibration of electrons of silver nanoparticles in resonance with light wave. A broad absorption peak was observed at $436 \mathrm{~nm}$, which is a characteristic band for the Ag. No other peak was observed in the spectrum which confirms that the synthesized products are Ag only.

FTIR measurement was carried out to identify the possible biomolecules responsible for capping and reducing agent for the Ag nanoparticles synthesized by tea leaf extract. Three obvious infrared bands are observed at $3271 \mathrm{~cm}^{-1}, 1637 \mathrm{~cm}^{-1}$ and $386 \mathrm{~cm}^{-1}$ (Figure 4). The intense broad band at $3271 \mathrm{~cm}^{-1}$ is due to $\mathrm{N}-\mathrm{H}$ and $\mathrm{O}-\mathrm{H}$ stretching mode in the linkage of the proteins. The medium intense band at $1637 \mathrm{~cm}^{-1}$ arises

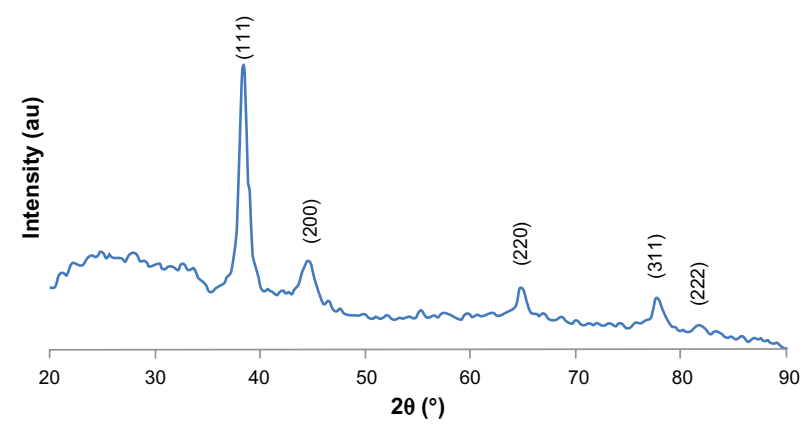

Figure 2 XRD patterns of $\mathrm{Ag}$ nanoparticles.

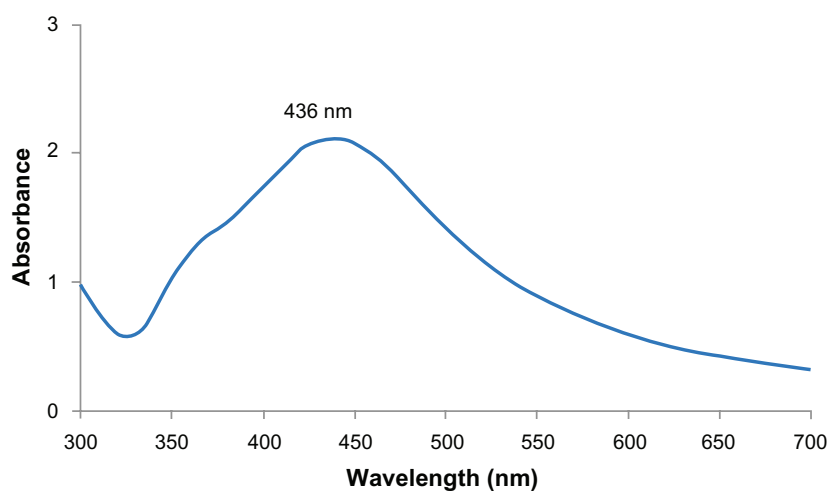

Figure 3 UV-vis spectrum of Ag nanoparticles.

from the $\mathrm{C}=\mathrm{O}$ stretching mode in amine I group which is commonly found in the protein, ${ }^{22}$ indicating the presence of proteins as capping agent for silver nanoparticles which increases the stability of the nanoparticles synthesized. On the other hand, the intense and broad peak at $386 \mathrm{~cm}^{-1}$ corresponded to the Ag metal.

Transmission electron microscopy (TEM) has been employed to characterize the size, shape and morphology of synthesized silver nanoparticles. The TEM image of silver nanoparticles is shown in Figure 5A. From the image, it is evident that the morphology of silver nanoparticles is spherical which is in agreement with the shape of SPR band in the UV-vis spectrum. Figure 5B shows the histogram of size distribution of silver nanoparticles. The average particles size measured from the TEM image is $4.06 \mathrm{~nm}$ which is in good agreement with the particle size calculated from XRD analysis.

The environmentally benign silver nanoparticles synthesis process have potential applications in verious fields. Silver nanoparticles can be applied in coating for solar energy, bio-labelling, food packaging, antimicrobial agent and drug delivery. ${ }^{23,24}$ Several studies on the usage of metal nanoparticles in the water filter have been carried out due to its antibacterial and as pesticide removal properties. ${ }^{25}$ Besides that, silver nanoparticles play an important role in

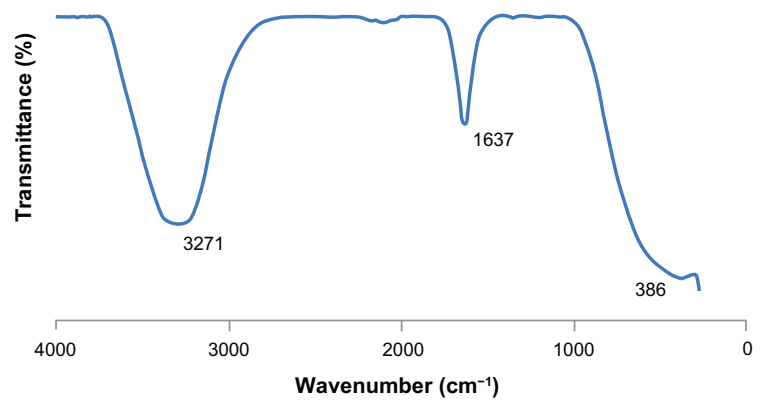

Figure 4 FTIR spectrum of $\mathrm{Ag}$ nanoparticles. 

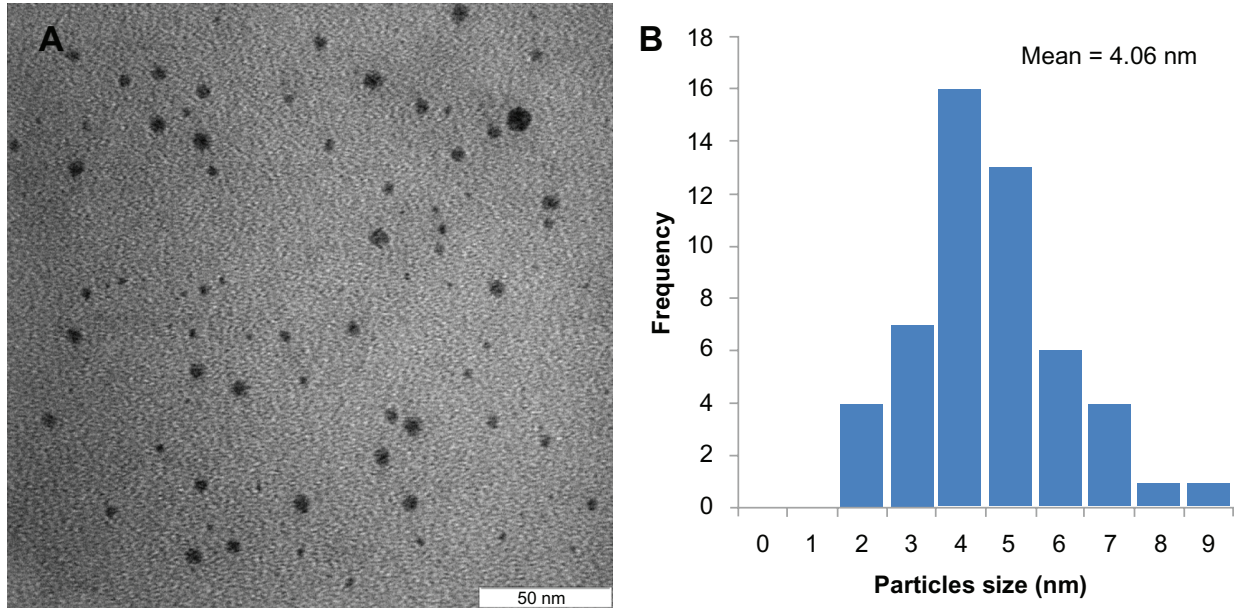

Figure 5 (A) TEM image and (B) particles size distribution of Ag nanoparticles synthesized by pu-erh tea leaves extract.

the medical area. Silver nanoparticles act as biomarker in detection of early diagnosis and therapy monitoring such as the detection of tumor for cancer treatment and early diagnosis for Alzheimer's disease. ${ }^{26}$

\section{Conclusion}

In this paper, we report a green approach for the synthesis of Ag nanoparticles using pu-erh tea leaves extract. This is a simple, green and efficient method to synthesize silver nanoparticles at room temperature without using any harmful reducing agents such as sodium borohydrite and any capping or dispersing agent. It was concluded that the green synthesized silver nanoparticles were composed of spherical particles which were highly crystalline. The particles sizes were controlled in the range from 2 to $10 \mathrm{~nm}$.

\section{Acknowledgments}

This study was supported by Fundamental Research Grant Scheme from the Ministry of Science, Technology and Innovation, Malaysia and in part by Grant-in-Aid for Scientific Research (KAKENHI 191010) from Japan Society for the Promotion of Sciences.

\section{Disclosure}

The authors report no conflicts of interest in this work.

\section{References}

1. Le A-T, Tam LT, Tam PD, et al. Synthesis of oleic acid-stabilized silver nanoparticles and analysis of their antibacterial activity. Materials Science and Engineering: C. 2010;30(6):910-916.

2. Huang H, Yang Y. Preparation of silver nanoparticles in inorganic clay suspensions. Composites Science and Technology. 2008;68(14): 2948-2953.
3. Yin H, Yamamoto T, Wada Y, Yanagida S. Large-scale and size-controlled synthesis of silver nanoparticles under microwave irradiation. Materials Chemistry and Physics. 2004;83(1):66-70.

4. Nadagouda MN, Speth TF, Varma RS. Microwave-Assisted Green Synthesis of Silver Nanostructures. Accounts of Chemical Research. 2011;44(7):469-478

5. Suber L, Sondi I, Matijevic E, Goia DV. Preparation and the mechanisms of formation of silver particles of different morphologies in homogeneous solutions. Journal of Colloid and Interface Science. 2005;288(2):489-495.

6. Song K, Lee S, Park T, Lee B. Preparation of colloidal silver nanoparticles by chemical reduction method. Korean Journal of Chemical Engineering. 2009;26(1):153-155.

7. Golubeva O, Shamova O, Orlov D, Pazina T, Boldina A, Kokryakov V. Study of antimicrobial and hemolytic activities of silver nanoparticles prepared by chemical reduction. Glass Physics and Chemistry. 2010; 36(5):628-634

8. Harada M, Kawasaki C, Saijo K, Demizu M, Kimura Y. Photochemical synthesis of silver particles using water-in-ionic liquid microemulsions in high-pressure CO2. Journal of Colloid and Interface Science. 2010; 343(2):537-545.

9. Harada M, Kimura Y, Saijo K, Ogawa T, Isoda S. Photochemical synthesis of silver particles in Tween 20/water/ionic liquid microemulsions. Journal of Colloid and Interface Science. 2009;339(2):373-381.

10. Li K, Zhang F-S. A novel approach for preparing silver nanoparticles under electron beam irradiation. Journal of Nanoparticle Research. 2010;12(4):1423-1428.

11. Bogle KA, et al. Silver nanoparticles: synthesis and size control by electron irradiation. Nanotechnology. 2006;17(13):3204.

12. Zhu J, Liu S, Palchik O, Koltypin Y, Gedanken A. Shape-Controlled Synthesis of Silver Nanoparticles by Pulse Sonoelectrochemical Methods. Langmuir. 2000;16(16):6396-6399.

13. El-Shishtawy RM, Asiri AM, Al-Otaibi MM. Synthesis and spectroscopic studies of stable aqueous dispersion of silver nanoparticles. Spectrochimica Acta Part A: Molecular and Biomolecular Spectroscopy. 2011;79(5):1505-1510.

14. Oei JD, Zhao WW, Chu L, et al. Antimicrobial acrylic materials with in situ generated silver nanoparticles. Journal of Biomedical Materials Research Part B: Applied Biomaterials. 2012;100B(2):409-415.

15. Kim K-J, Sung W, Suh B, et al. Antifungal activity and mode of action of silver nano-particles on Candida albicans. Bio Metals. 2009;22(2): 235-242.

16. Nadworny P, Wang J, Tredget E, Burrell R. Anti-inflammatory activity of nanocrystalline silver-derived solutions in porcine contact dermatitis. Journal of Inflammation. 2010;7(1):13. 
17. Lara H, Ayala-Nunez N, Ixtepan-Turrent L, Rodriguez-Padilla C. Mode of antiviral action of silver nanoparticles against HIV-1. Journal of Nanobiotechnology. 2010;8(1):1.

18. Kalishwaralal K, Banumathi E, Pandian SRK, et al. Silver nanoparticles inhibit VEGF induced cell proliferation and migration in bovine retinal endothelial cells. Colloids and Surfaces B: Biointerfaces. 2009;73(1): 51-57.

19. Shrivastava S, Bera T, Singh SK, Singh G, Ramachandrarao P, Dash D. Characterization of Antiplatelet Properties of Silver Nanoparticles. ACS Nano. June 23, 2009;3(6):1357-1364.

20. Atiyeh BS, Costagliola M, Hayek SN, Dibo SA. Effect of silver on burn wound infection control and healing: Review of the literature. Burns. 2007;33(2):139-148.

21. Jeng K-C, Chen C-S, Fang Y-P, Hou RC-W, Chen Y-S. Effect of Microbial Fermentation on Content of Statin, GABA, and Polyphenols in Pu-Erh Tea. Journal of Agricultural and Food Chemistry. October 1, 2007;55(21):8787-8792.
22. Jiale H, Qingbiao L, Daohua S, et al. Biosynthesis of silver and gold nanoparticles by novel sundried Cinnamomum camphora leaf. Nanotechnology. 2007;18(10):105104.

23. Philip D. Mangifera Indica leaf-assisted biosynthesis of well-dispersed silver nanoparticles. Spectrochimica Acta Part A: Molecular and Biomolecular Spectroscopy. 2011;78(1):327-331.

24. Kouvaris P, Delimitis A, Zaspalis V, Papadopoulos D, Tsipas SA, Michailidis N. Green synthesis and characterization of silver nanoparticles produced using Arbutus Unedo leaf extract. Materials Letters. 2012;76(0):18-20.

25. Jain P, Pradeep T. Potential of silver nanoparticle-coated polyurethane foam as an antibacterial water filter. Biotechnology and Bioengineering. 2005;90(1):59-63.

26. Singh M, Singh S, Prasad S, Gambhir IS. Nanotechnology in Medicine and Antibacterial Effect of Silver Nanoparticles. Digest Journal of Nanomaterials and Biostructures. 2008;3(3):115-122.
International Journal of Nanomedicine

\section{Publish your work in this journal}

The International Journal of Nanomedicine is an international, peerreviewed journal focusing on the application of nanotechnology in diagnostics, therapeutics, and drug delivery systems throughout the biomedical field. This journal is indexed on PubMed Central, MedLine, CAS, SciSearch $\AA$, Current Contents ${ }^{\circledR} /$ Clinical Medicine,

\section{Dovepress}

Journal Citation Reports/Science Edition, EMBase, Scopus and the Elsevier Bibliographic databases. The manuscript management system is completely online and includes a very quick and fair peer-review system, which is all easy to use. Visit http://www.dovepress.com/ testimonials.php to read real quotes from published authors.

Submit your manuscript here: http://www.dovepress.com/international-journal-of-nanomedicine-journal 